\title{
Evaluated of Mechanical Properties for Aluminum Alloy Using Taguchi Method
}

\author{
Sahira Hassan Ibrahim * Sahar Hussein Ahmed ** Iman Ahmed Hameed * \\ * Mechanical Engineering Department \\ ** Material Engineering Department \\ University of Technology, Iraq, 2015
}

\begin{abstract}
AA7075 is one of significant industrial aluminum alloys, its special mechanical properties such as strength and ductility has makes it used in varying applications. In this investigation a heat treatment process has been done after quenching in water in deferent temperatures and times, the mechanical properties (tensile strength \& hardness) have been tested and the results have been designed by Taguchi method to predict the optimum strength and hardness values. The process parameters which a key role in deciding this study, were three tempering temperature $(100,200,300){ }^{\circ} \mathrm{C}$, three time holding $(1,2,3) \mathrm{hr}$, three temperature rise rate $(5,10,15)^{\circ} \mathrm{C} / \mathrm{min}$. Taguchi parametric design and optimization approach was used Minitabl7 program to analyze the data find the optimal strength and hardness for improvement mechanical behavior of AA7075 aluminum alloy. The results found that optimum strength at parameters $\left(100^{\circ} \mathrm{C}, 5^{\circ} \mathrm{C} / \mathrm{min}, 1 \mathrm{Hr}\right) \&$ the optimum hardness at parameters $\left(100^{\circ} \mathrm{C}, 5^{\circ} \mathrm{C} / \mathrm{min}, 2 \mathrm{Hr}\right)$.
\end{abstract}

Keywords: AA7075, Heat Treatment, Taguchi Method, Minitab17

\section{INTRODUCTION}

Aluminum alloy has a wide range of applications in aerospace, automotive, building and many other fields; AA7075 aluminum alloy is one of the most expensive and benefit alloy because of its high strength and corrosion resistance. The heat treatment processes, commonly used to improve the properties of aluminum alloys, which are: solution heat treatment, precipitation hardening (age hardening), and annealing. Solution heat treatment is used to redistribute the alloying constituents that segregate from the aluminum during cooling from the molten state. It consists of heating the alloy to a temperature at which the soluble constituents will form a homogeneous mass by solid diffusion, holding the mass at that temperature until diffusion takes place, then quenching the alloy rapidly to retain the homogeneous condition. In the quenched condition, heat-treated alloys are supersaturated solid solutions that are comparatively soft and workable, and unstable, depending on composition. At room temperature, the alloying constituents of some alloys (W temper) tend to precipitate from the solution spontaneously, causing the metal to harden in about four days. This is called natural aging. It can be retarded or even arrested to facilitate fabrication by holding the alloy at sub-zero temperatures until ready for forming Annealing is used to effect recrystallization, essentially complete precipitation, or to remove internal stresses. For most alloys, annealing consists of heating to about $650^{\circ} \mathrm{F}\left(343^{\circ} \mathrm{C}\right)$ at a controlled rate. The rate is dependent upon such factors as thickness, type of anneal desired, and method employed. Cooling rate is not important, but drastic quenching is not recommended because of the strains produced. [1].there is many research deal with heat treatment of aluminum alloys, Suleiman E. et al [2] investigated various time and temperature to find the best combination to increased its hardness. Dorward RC.et al [3] illustrated the effects of ( $\mathrm{Mn}, \mathrm{Cr})$ elements in prevent precipitation of $(\mathrm{Mg}, \mathrm{Si})$ on grain boundaries; from the results there is reduce in intergranular breakage targets and the effect of $(\mathrm{Mn})$ on the hardness is the integration of deformation, also a refined grain size. Markandeya. R and Sarma. D [4] concluded that the age hardening through precipitation strengthens $(\mathrm{Al}-\mathrm{Cu}, \mathrm{Al}-\mathrm{Si})$ alloys, this heat treatment improving the mechanical properties of aluminum alloys .Sun. Y [5] emphasize that deformation impact in sample of cooling and aging has positive effect on hardness and strength.

\section{Taguchi Method \&Minitab Program}

Taguchi Approach is a standardized form of experimental design technique, its involve reducing the variation in a process through robust design of experiments. The overall objective of the method is to 
produce high quality product at low cost to the manufacturer. It was developed by Dr.Genichi Taguchi in Japan who developed a method for designing experiments to investigate how different parameters affect the mean and variance of a process performance characteristic that defines how well the process is functioning [6]. There are many ways to compute the analysis of variance: general linear models, Statistical Package for Social Sciences (SPSS) and Minitab; this program is designed to provide a simple, effective way to input statistical data, manipulate that data, identify trends and patterns, and then extrapolate answers to the problem at hand. That's a rather simplistic way of describing this vital and extremely effective tool [7].

\section{Experimental Procedure}

\subsection{Materials Specifications}

AA7075 aluminum alloy plate of $6 \mathrm{~mm}$ thickness was used; the specimen has the chemical composition as shown in Table 1.

Table1. Chemical Composition for the (AA7075)

\begin{tabular}{|c|c|c|c|c|c|c|c|}
\hline Sample & \% Si & \%Fe & \%Cu & \%Mn & \%Mg & \%Zn & \%Cr \\
\hline AA7075 & Max0.4 & Max 0.5 & 1.8 & Max 0.3 & 2.1 & 5.4 & 0.21 \\
\hline
\end{tabular}

For this study the standard tensile test used according to (ASTM E8M-04) shown in Fig 1. The samples show in FigA.

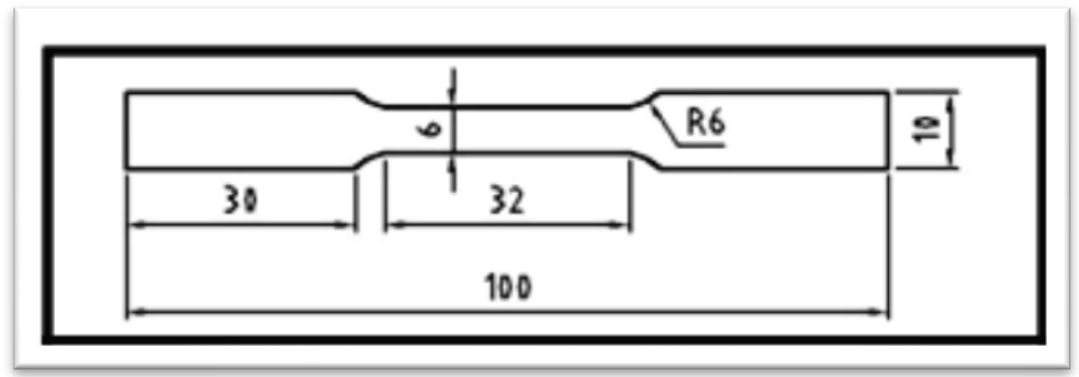

Fig1. Tensile Test Specimen (ASTM E8M-04)

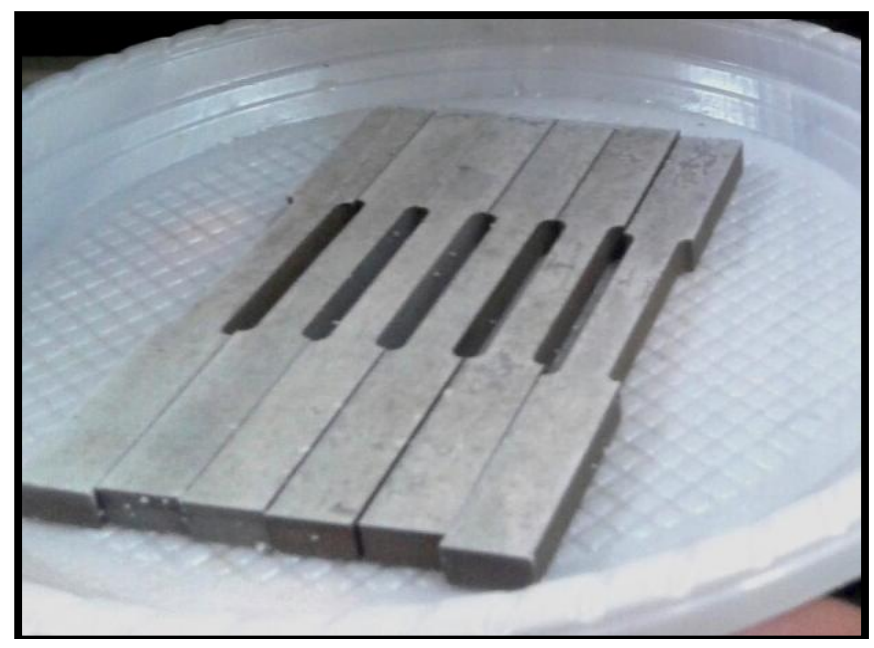

FigA. Tensile Strength Test Samples

\section{Heat Treatment Requirements}

For aluminum alloy AA7075 the specimens are heated in electrical furnace at 900 of (480 OC) for $2 \mathrm{~h}$ and followed by quenching in water in the room temp, the samples were kept in freezer to avoid natural aging.

\subsection{Process Parameters}

Three parameter have been determined: a) temperature heat $(\mathrm{OC}), \mathrm{b})$ rate of temperature rise (OC /min), c) heat time stay (hour ), the three levels was determined including the minimum and maximum values, the parameters and their levels are fixed in Table 2 . 
Evaluated of Mechanical Properties for Aluminum Alloy Using Taguchi Method

Table2. Parameters and Their Levels

\begin{tabular}{|c|c|c|c|}
\hline Factures & Level 1 & Level 2 & Level 3 \\
\hline Temperature Heat $\mathrm{TH}\left[{ }^{\mathrm{O}} \mathrm{C}\right]$ & 100 & 200 & 300 \\
\hline Temperature Rise Rate $\mathrm{TR}\left[{ }^{\mathrm{O}} \mathrm{C} / \mathrm{Min}\right]$ & 5 & 10 & 15 \\
\hline Time Stay & 1 & 2 & 3 \\
\hline
\end{tabular}

\subsection{Design the Matrix Experiment (OA)}

After the parameters affecting a process and the levels determined. Typically, the number of levels for all parameters in the experimental design is chosen to be the same to aid in the selection of the proper orthogonal array. For the three parameters and three levels that specified above, it was found that the appropriate orthogonal array is L9 (43): as shown in Table3.

Table3. Orthogonal Array L9 (43) With Actual Variables and Stat

\begin{tabular}{|c|c|c|c|}
\hline Experiment & TH $\left[{ }^{\mathbf{0}} \mathbf{C}\right]$ & TR $\left[{ }^{\mathbf{0}} \mathbf{C} / \mathbf{M i n}\right]$ & TIS [Hour] \\
\hline 1 & 100 & 5 & 1 \\
\hline 2 & 100 & 10 & 2 \\
\hline 3 & 100 & 15 & 3 \\
\hline 4 & 200 & 5 & 2 \\
\hline 5 & 200 & 10 & 1 \\
\hline 6 & 200 & 15 & 3 \\
\hline 7 & 300 & 5 & 1 \\
\hline 8 & 300 & 10 & 2 \\
\hline 9 & 300 & 15 & \\
\hline
\end{tabular}

In this study the ultimate tensile strength (UTS), yield tensile strength (YS) and Rockwell hardness (HRB), Vickers (HV) tests have been done; the results have been fixed in Table4.the tested samples and devices used shown in $\operatorname{Fig}(\mathrm{B}, \mathrm{C}, \mathrm{D})$.

Table4. Results for Each Experiment

\begin{tabular}{|c|c|c|c|c|c|c|c|}
\hline $\begin{array}{c}\text { Experiment } \\
\text { number }\end{array}$ & $\begin{array}{c}\text { TH } \\
{\left[{ }^{\mathbf{0}} \mathbf{C}\right]}\end{array}$ & $\begin{array}{c}\text { TR } \\
{\left[{ }^{\mathbf{0}} \mathbf{C} \text { /Min] }\right.}\end{array}$ & TIS $[$ Hour $]$ & $\begin{array}{c}\text { UTS } \\
{[\mathbf{M P a}]}\end{array}$ & $\begin{array}{c}\text { YS } \\
{[\mathbf{M P a}]}\end{array}$ & Rockwell HRB & $\begin{array}{c}\text { Vickers } \\
\text { HV }\end{array}$ \\
\hline Standard & & & & 572 & 503 & 87 & 175 \\
\hline Quenching & 480 & 10 & 2 & 564 & 556 & 74 & 140 \\
\hline 1 & 100 & 5 & 1 & 483 & 445 & 48 & 100 \\
\hline 2 & 100 & 5 & 2 & 482 & 402 & 56 & 110 \\
\hline 3 & 100 & 5 & 3 & 492 & 492 & 51 & 105 \\
\hline 4 & 200 & 10 & 1 & 492 & 477 & 51 & 105 \\
\hline 5 & 200 & 10 & 2 & 468 & 442 & 47 & 100 \\
\hline 6 & 200 & 10 & 3 & 426 & 426 & 43 & 95 \\
\hline 7 & 300 & 15 & 1 & 269 & 264 & 36 & 90 \\
\hline 8 & 300 & 15 & 2 & 260 & 56 & 34 & 86 \\
\hline 9 & 300 & 15 & 3 & 259 & 33 & 28 & 80 \\
\hline
\end{tabular}

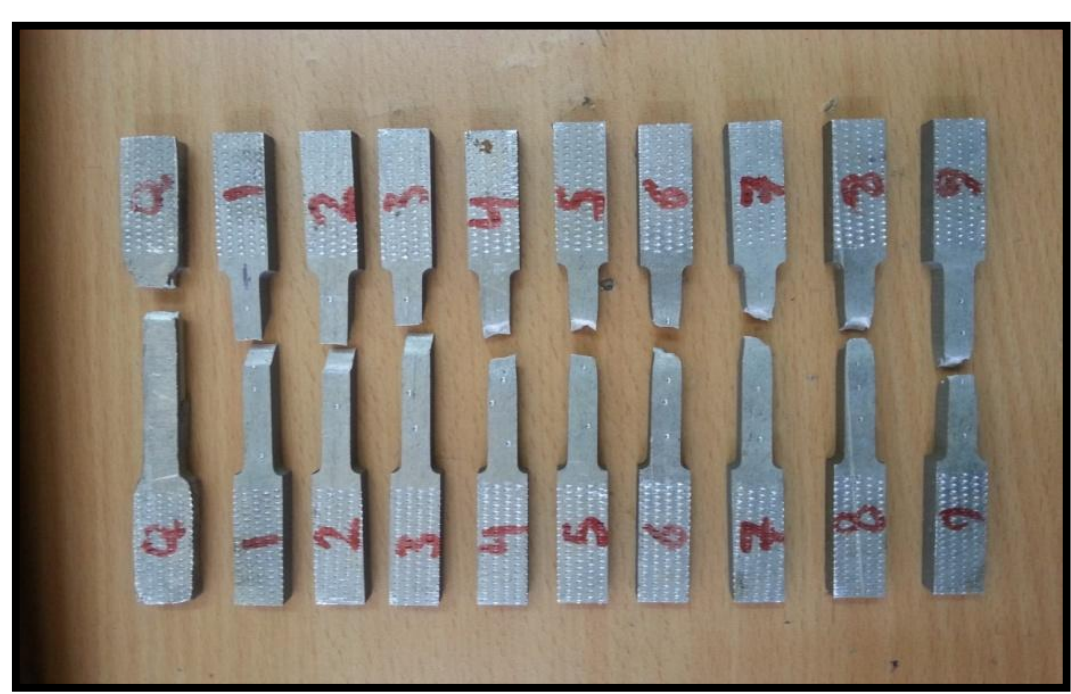

FigB. Tensile Strength Test Samples 


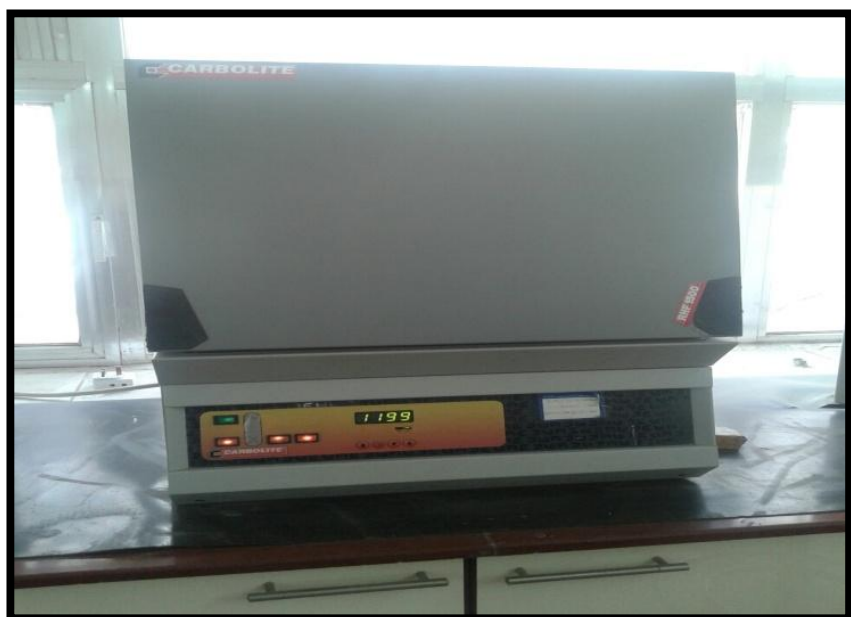

FigC. Electric Furnace

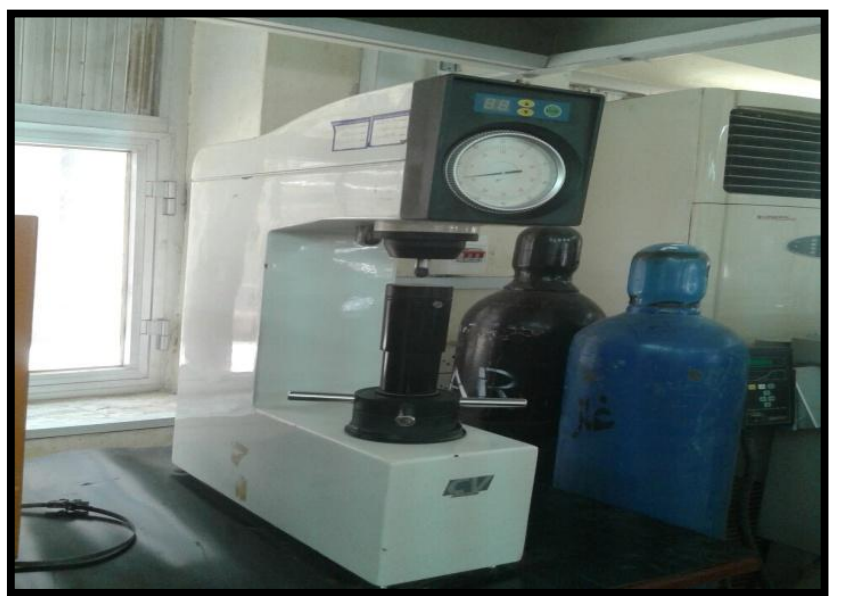

FigD. Rockwell Hardness Test Samples

The graphs obtained from tensile test shown in Figures (E1 to E9) respectively.
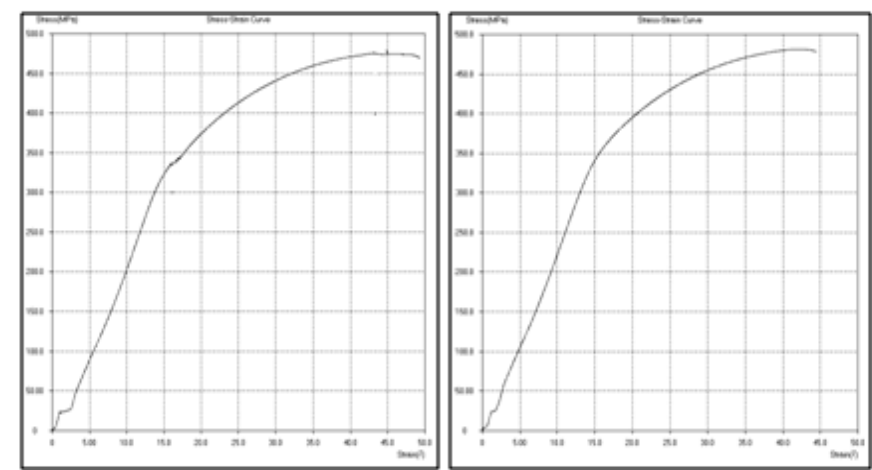

Fig El stress-strain at $\left(100^{\circ} \mathrm{co}, 5^{\circ} \mathrm{c} / \mathrm{min}, 1 \mathrm{~h}\right)$

Fig E2 stress-strain at ( $\left.100^{\circ} \mathrm{c}, 10^{\circ} \mathrm{c} / \mathrm{min}, 2 \mathrm{~h}\right)$
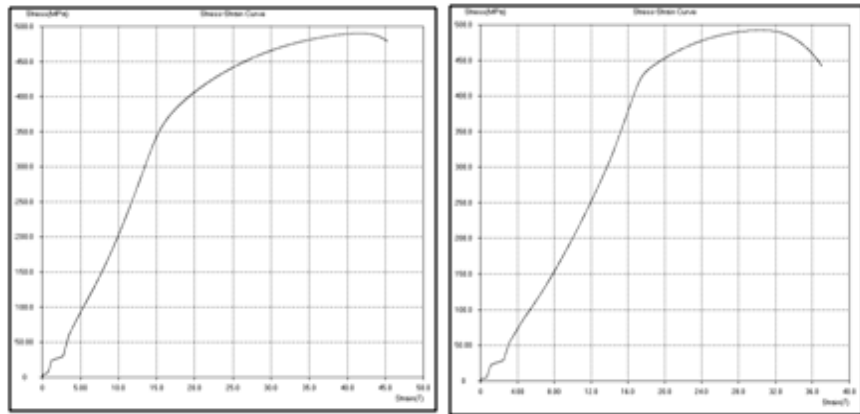

Fig E3 stress-strain at $\left(100^{\circ} c_{0} 15^{\circ} / \mathrm{min}, 3 \mathrm{~h}\right)$

Fig E4 stress-strain at (200 $\left.{ }^{\circ}, 5_{0}^{\circ} \mathrm{c} / \mathrm{min}, 2 \mathrm{~h}\right)$ 

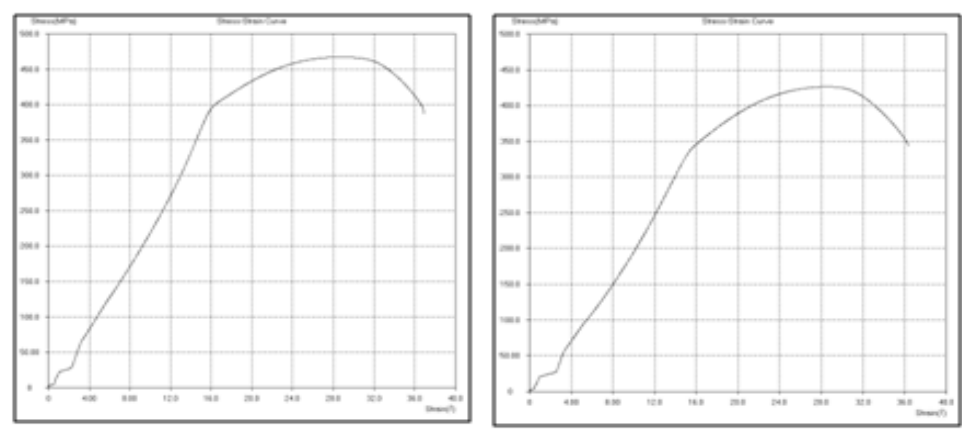

Fig E5 stress-strain at $\left(100^{\circ}{ }_{6}^{\circ} 5^{\circ} \mathrm{c} / \mathrm{min}, 1 \mathrm{~h}\right)$

Fig E6 stress-strain at $\left(200^{\circ}, 10^{\circ} \mathrm{c} / \mathrm{min}, 3 \mathrm{~h}\right)$
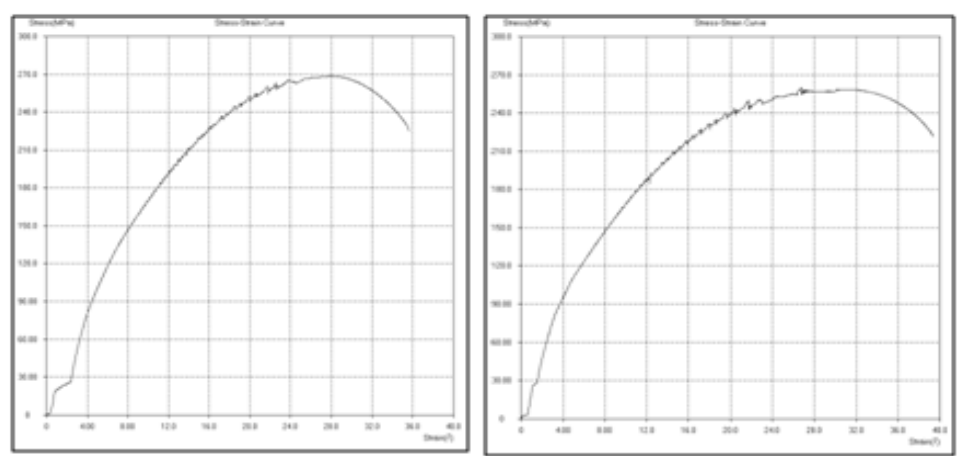

Fig $\mathrm{E} 7$ stress-strain at $\left(300^{\circ} \mathrm{c}, 5^{\circ} \mathrm{c} / \mathrm{min}, 3 \mathrm{~h}\right)$

Fig ES stress-strain at $\left(300^{\circ} \mathrm{co}, 10^{\circ} \mathrm{c} / \mathrm{min}, 1 \mathrm{~h}\right)$

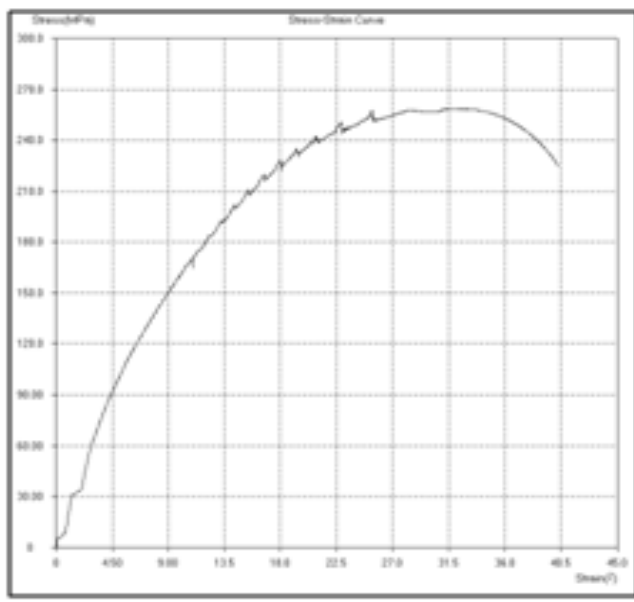

Fig E9 stress-strain at (300 $\left.{ }^{\circ}, 15^{\circ} \mathrm{c} / \mathrm{min}, 2 \mathrm{~h}\right)$

\section{Data Analysis Procedure Software}

Minitab17 program has chosen to analysis the data that obtained from tested samples,. The program interface used to run the data shown in Fig2.

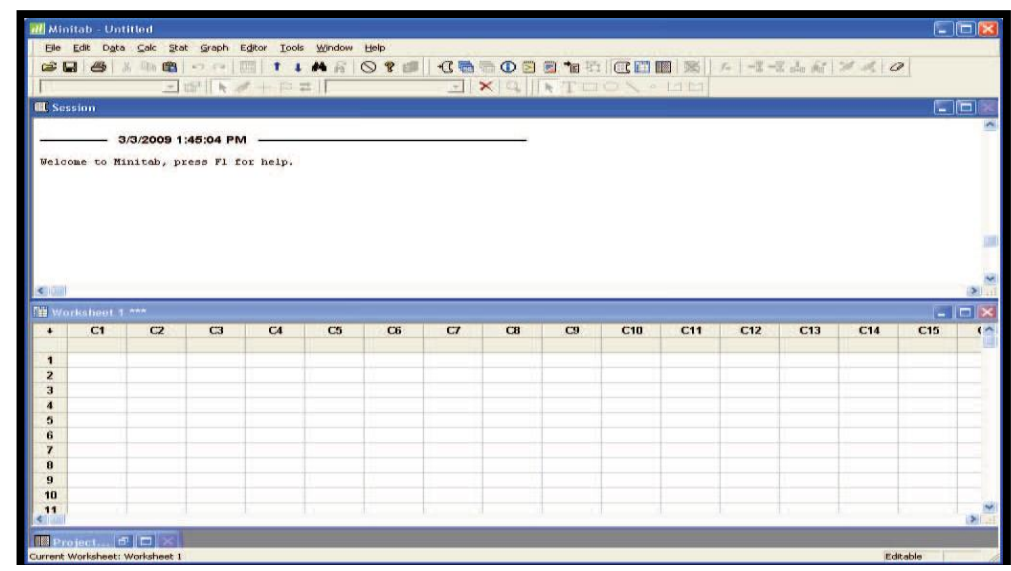

Fig2. Minitab Program Interface 
In this study to analyzing experimental data, the results take from Table5 put in the worksheet this step show in Fig3.

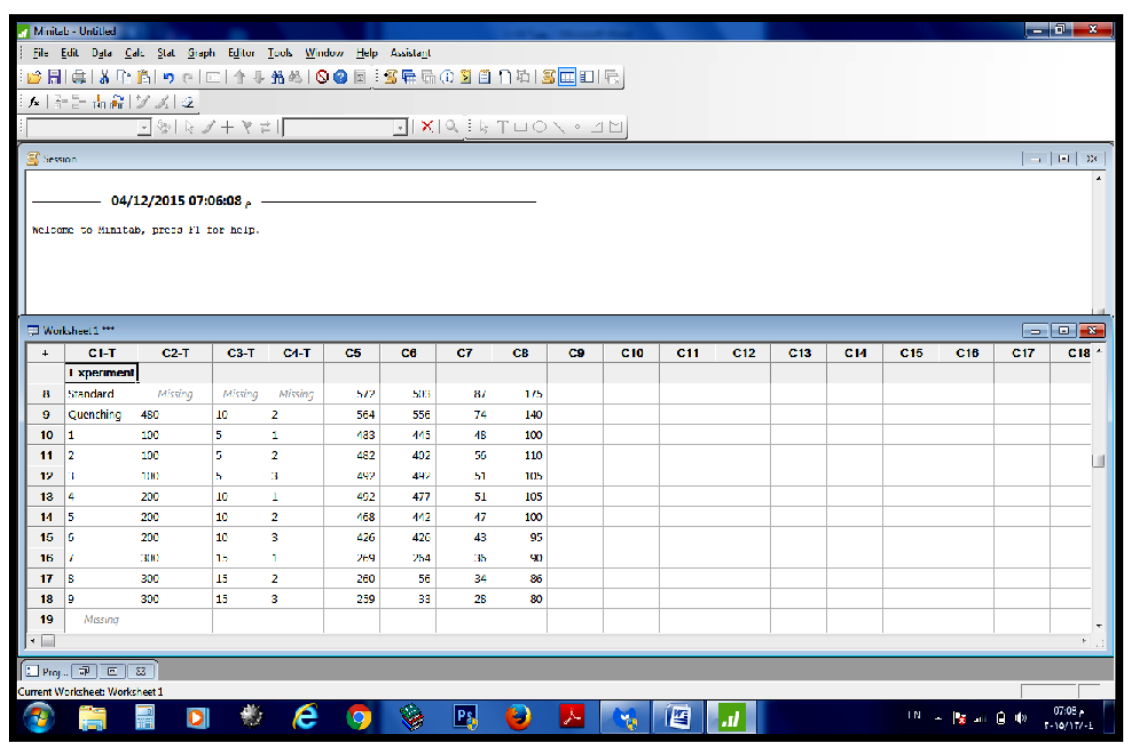

Fig3. Minitab Program Worksheet

To create Taguchi design from data in worksheet the steps, 1 st open the stat from menu bar ,2nd open DOE ,3rd open Taguchi ,4th open define Taguchi custom design as shows in fig4.

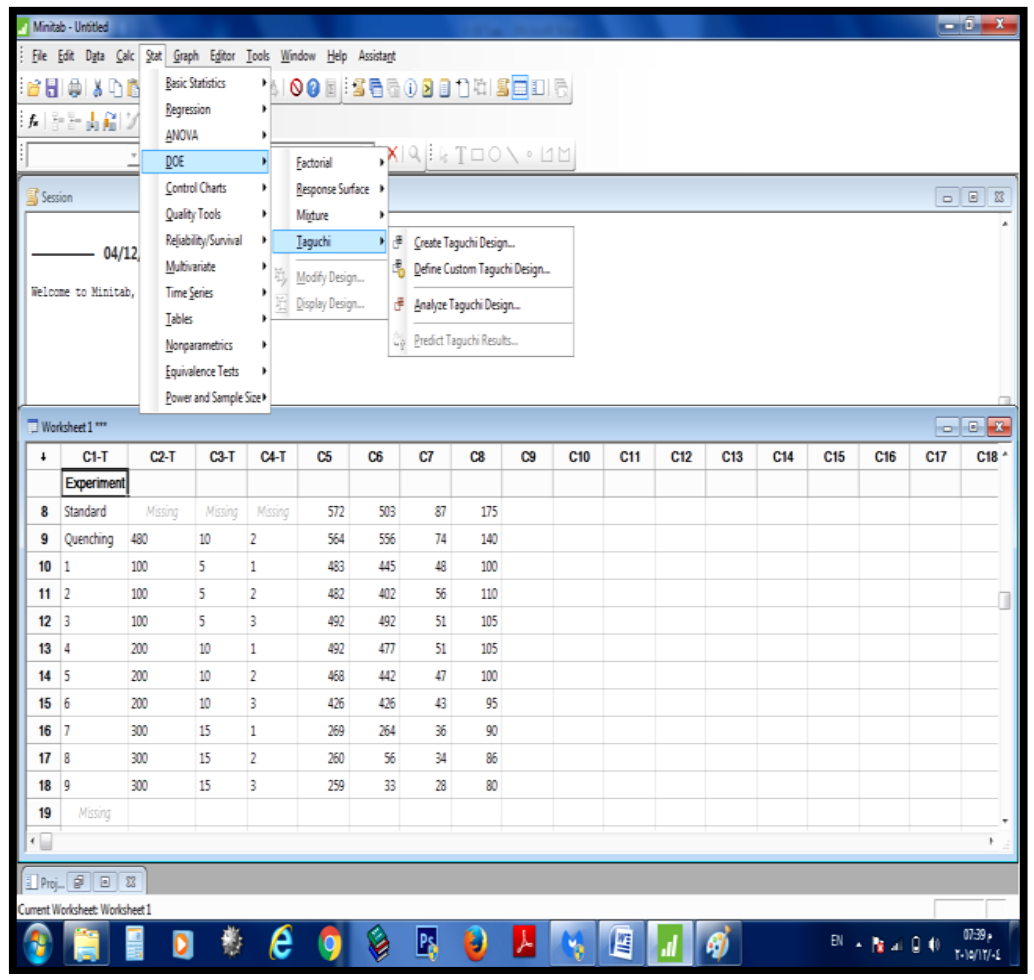

Fig4. Minitab Program Taguchi Design

The program well analyzed the given data each factor separately while the three parameter stay constant to find the first response, the ultimate tensile strength was selected and the option chose to be the larger is the better that because in Taguchi analyze there are three criterions which are (the larger is the better, the smaller is the better, the nominal is the better) depend on what the study deal with. The mean aid for this study is to find the optimum parameters to maximize the strength and hardness. The mean values were selected to plot.

\section{RESUlt AND DISCUSSION}

To analyze the Taguchi design after the data defined the program running to give the graphs as shown in Fig 5,6,7,8. 


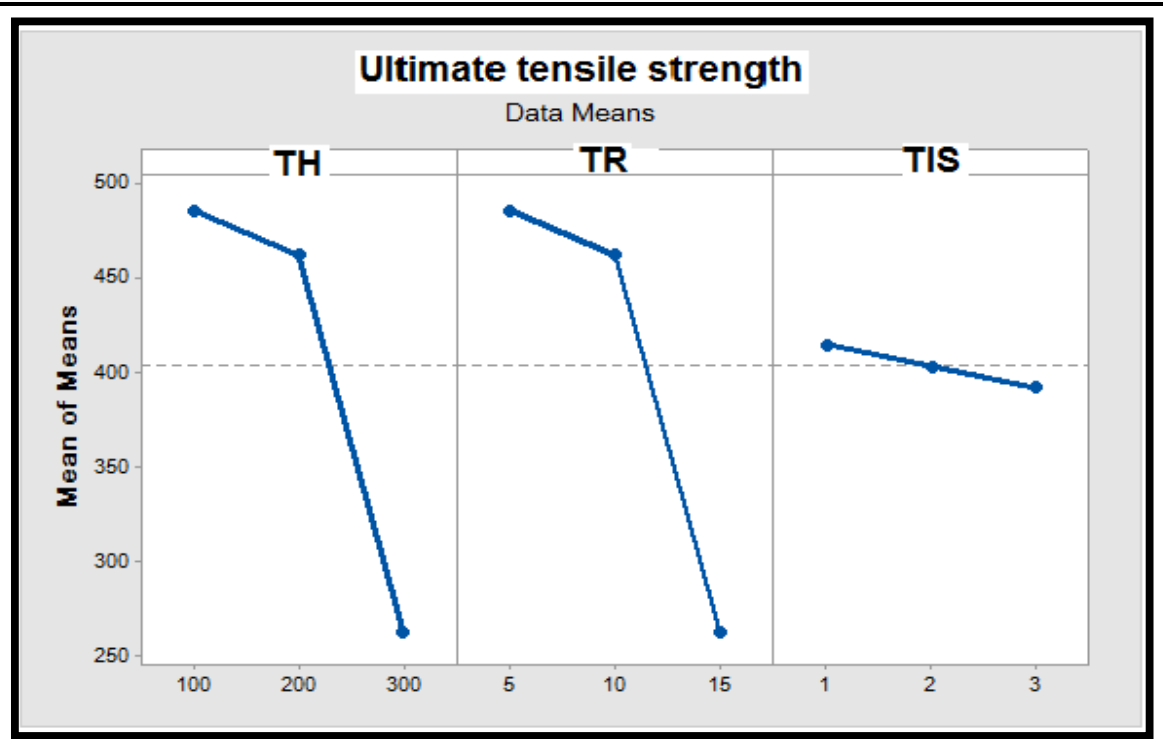

Fig5. Mean Effect Plot for Ultimate Tensile Strength (UTS)

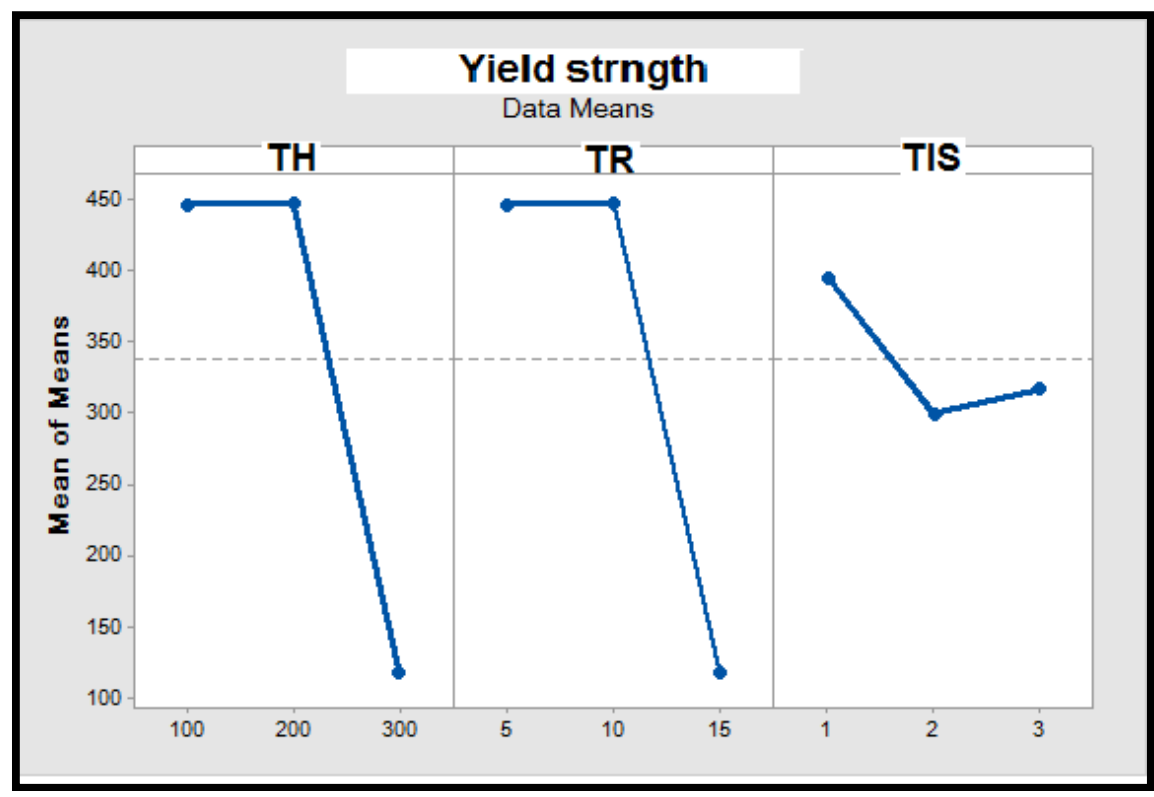

Fig6. Mean Effect Plot for Yield Strength

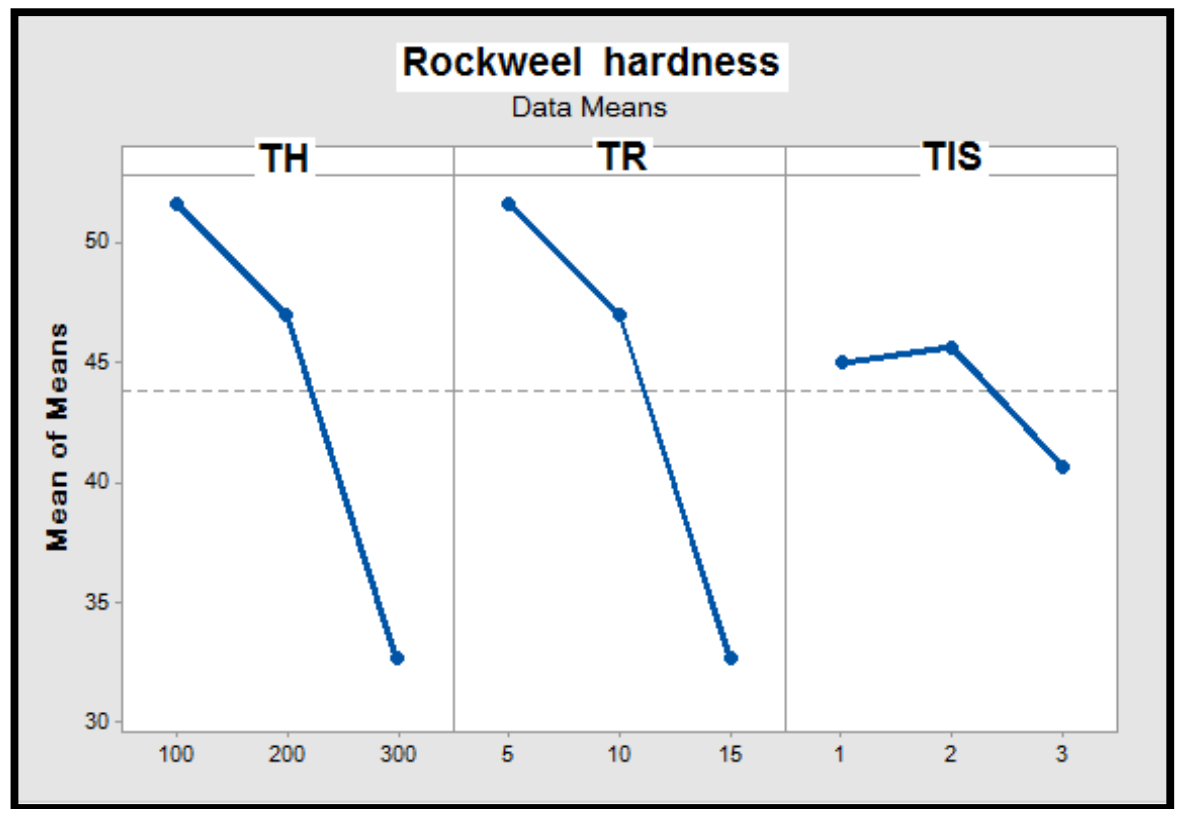

Fig7. Mean Effect Plot for Rockwell Hardness 


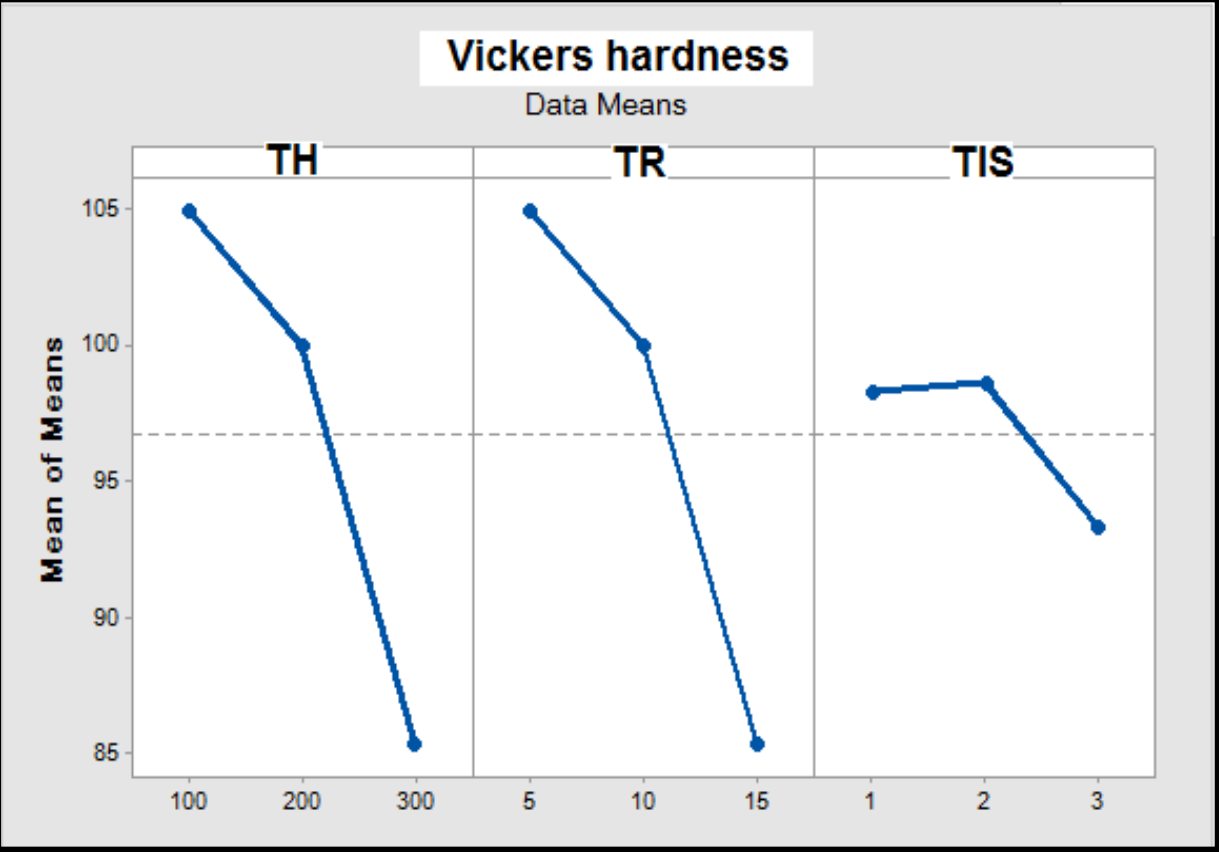

Fig4. Mean Effect Plot for Vickers Hardness

The highest value from each factor considered the best and chosen to be the optimum parameter where from the graphs the values but as shown in Table 5 .

Table5. Best Setting of Combination Parameters

\begin{tabular}{|c|c|c|c|}
\hline \multirow{2}{*}{ Factures } & \multicolumn{3}{|c|}{ Parameters } \\
\cline { 2 - 4 } & $\mathrm{TH}\left[{ }^{\circ} \mathrm{C}\right]$ & $\mathrm{TR}\left[{ }^{0} \mathrm{C} / \mathrm{Min}\right]$ & $\mathrm{TIS}[\mathrm{Hr}]$ \\
\hline Ultimate Tensile Strength (UTS) & 100 & 5 & 1 \\
\hline Yield Tensile Strength (YS) & $100-200$ & $5-10$ & 1 \\
\hline Rockwell Hardness (HRB) & 100 & 5 & 2 \\
\hline
\end{tabular}

The predict of optimum indicate that ultimate strength has the greatest values when the degree of tempering $100 \mathrm{OC}$ rising $5 \mathrm{OC} / \mathrm{Min}$ and stay for $1 \mathrm{hr}$, the yield strength has 100-200 OC, 5-10 OC /Min, 1hr, the Rockwell hardness has the larger value at 100 OC, 5 OC /Min, $2 \mathrm{hr}$.

\section{CONCLUSION}

This study has proven that optimizing multi response parameters by using Taguchi method of experimental design can help us reducing time taken to test the experiments by using the appropriate program were the system was design to give a specified target quality of the heat treatment process. And lead to the consequent below.

- From the experimental results, found that optimum parameters for ultimate tensile strength were $\left(100{ }^{\circ} \mathrm{C}, 5^{\circ} \mathrm{C} / \mathrm{min}, 1 \mathrm{hr}\right)$

- From the experimental results, found that optimum parameters for yield tensile strength were $\left(100-200{ }^{\circ} \mathrm{C}, 5-10^{\circ} \mathrm{C} / \mathrm{min}, 1 \mathrm{hr}\right)$

- From the experimental results, found that optimum parameters for hardness were $\left(100{ }^{\circ} \mathrm{C}, 5\right.$ ${ }^{\circ} \mathrm{C} / \mathrm{min}, 2 \mathrm{hr}$ )

\section{REFERENCES}

[1] Military Standardization, “Aluminum and Aluminum Alloys”, handbook, 1999.

[2] Suleiman E. Mohammad E. Hussien M and Ala M, "Heat Treatment of Aluminum Alloy 7449", International Journal of Metallurgical Engineering, VOL7, 2013.

[3] Dorward Rc and Bouvier C, " A Rationalization of Factors Affecting Strength, Ductility and Toughness of AA6061 ”, Journal of Material Science Engineering ,1998.

[4] Markandeya RSN and Sarma DS," Precipitation Hardening of (Cu-Ti-Zr) Alloy", Journal of Material Science Engineering, 2004. 
[5] Sun y,et al, " the effect of deformation before aging on wear resistance of aluminum alloy", 1999.

[6] Stephanie Fraley et al, " Design of Experiments via Taguchi Methods: orthogonal arrays", 2007.

[7] C.Vidal et al, "Application of Taguchi Method in the Optimization of FSW Parameters of an Aeronautic Aluminum Alloy", Department of Mechanical Engineer, Portugal, 2009. 